\title{
What is going on around you: Peer milieus and educational aspirations
}

Isabel J. Raabe (corresponding author)

Institute of Sociology, University of Zürich, Switzerland

and

Chair of Social Networks, ETH Zürich, Switzerland.

Ralf Wölfer

Department of Experimental Psychology, University of Oxford, United Kingdom.

\section{Acknowledgements}

We are grateful for support from Jan O. Jonsson and Zsófia Boda, as well as for valuable feedback from the group from the Chair Social Networks at the ETH Zürich.

\section{Contact information}

Isabel J. Raabe

Institute of Sociology, University of Zürich

Andreasstrasse 15

8050 Zürich

Switzerland

isabel.raabe@uzh.ch 


\title{
What is going on around you: Peer milieus and educational aspirations
}

\author{
Peers have long been found to be of relevance for educational aspirations and hence \\ educational success. While sociological and social psychological theories often assume \\ concrete social mechanisms that focus on "significant" peers, past research \\ predominantly had to rely on classroom-level aggregates. This study examines how \\ educational aspirations among adolescents cluster in friendship networks within school \\ classes. Through the utilisation of social network measures from the CILS4EU data on \\ Germany, the Netherlands, and Sweden (15,203 individuals, 50\% girls, $\mathrm{M}_{\mathrm{AGE}} 14.9$ \\ years), we construct two measures of the most significant peers around individuals, i.e. \\ of the peer milieu, and explore the salience of educational aspirations in these milieus. \\ Applying longitudinal logistic regression models and first-difference models with \\ individual-level fixed effects, we find evidence for clustering of individuals with the \\ same educational aspirations within classrooms, underlining the relevance of peers for \\ educational success.
}

\section{Introduction}

What adolescents consider of value, their hopes, and their expectations for the future, are shaped within their families, the school context, and through their peers. While the family forms the baseline of individuals' educational aspirations, dependent on e.g. socioeconomic and migration background, the school context and individuals' interaction with their peers become more important throughout adolescence. In fact, it is assumed that for adolescents, peers provide the more significant frame of reference compared to parents, due to time spent together and similar life circumstances (Brechwald \& Prinstein, 2011; Osterman, 2000; Youniss \& Smollar, 1985). Peer effects have thus been extensively researched in the past, in a variety of areas of social sciences, often conceptualised as an aggregate of characteristics of a wider social context, such as the school class or the neighbourhood (e.g. Rjosk et al., 2014; van Ewijk \& Sleegers, 2010). 
Values and attitudes, such as educational aspirations, however, are not spread uniformly throughout a social system. This has not only been proposed in theoretical works, emphasising the need to take into account interactions and social structures (Fine \& Kleinman, 1979), but it has also been shown empirically that in classrooms "some are more peer than others" (Lomi, Snijders, Steglich, \& Torló, 2011). Peer selection and socialisation create and maintain socially embedded sets of attitudes, values or norms: specific peer cultures. These can be understood as subcultures within the larger classroom context, i.e. cultures that are distinct from what is considered the mainstream culture (M. Sherif \& Sherif, 1964). When educational aspirations, which have important implications and effects for educational performance, are part of such peer cultures, they are likely to stabilise and persist, since they reinforced as part of the culture.

Classrooms themselves vary significantly in the extent to which students in them aspire to specific educational careers, due to initial sorting into specific schools based on parental socioeconomic status, the school culture, and teacher effects. At the same time, however, peer processes are likely to lead to additional within-classroom variation. So far, culture has often been studied based solely on content rather jointly with structure, although this is an inherent feature (Pachucki \& Breiger, 2010). In this study, we examine the extent to which educational aspirations are embedded in peer clusters within school classrooms. Through the utilisation of social network data, we do not only add to our understanding of the way adolescents hold educational aspirations in general, but we also improve the fit of theory and empirical analysis on peer and subcultures. This is furthermore strengthened by the fact that our study is able to account for the reference of peer subcultures in the classroom, i.e. the remainder of individuals in the classroom, which has been a long-standing criticism of much existing research (Fine \& Kleinman, 1979).

\section{The importance of educational aspirations on individuals' careers}

A number of studies in different branches of social sciences have documented that educational and occupational outcomes are strongly affected by an individual's aspirations (Feliciano \& Rumbaut, 2005; Portes, Aparicio, Haller, \& Vickstrom, 2010). This is mainly explained by the potential of aspirations to increase motivation and the tendency to make more ambitious career choices. Similarly 
to social class (Boudon, 1974), aspirations are thus affecting educational performance and choices which are considered to explain educational outcomes (Erikson \& Jonsson, 1996; Jackson, 2013). Since educational success carries implications for the level and type of possible occupation, aspirations continue their significance for labour market outcomes as well.

Various factors have been identified to affect educational aspirations, which are related to family background, such as socioeconomic or migration background. There is, for example, the idea that values regarding the worth of education differ between social classes. In particular, this refers to children from upper or middle classes being socialised into a value system that puts higher regard on education, in comparison to children who grow up in a working class environment. This can play out in different risk-avoiding career behaviours, such as taking out student loans, or following a career path which does not lead to a pre-defined occupation, but has higher earning potential (Jonsson \& Rudolphi, 2011). Furthermore, individuals with a migration background have been found to hold on average higher educational aspirations than majority peers who perform equally well in school (Brinbaum \& Cebolla-Boado, 2007; Jackson, Jonsson, \& Rudolphi, 2012). The relatively higher aspirations have been found to explain the tendency of adolescents with a migration background being more successful in school than their native peers from the same socioeconomic background (Heath, Rothon, \& Kilpi, 2008).

\section{How social connections shape aspirations}

Research has repeatedly documented how individuals' values and goals are shaped by the social context, besides the baseline differences mentioned above. In this vein, the seminal Wisconsin Model of status attainment, that explicitly considers aspirations, emphasises the effects of "significant" peers and teachers, besides the family (Sewell, Haller, \& Portes, 1969). This is in line with results indicating that peers, who are usually in the school context, become relatively more important to individuals throughout adolescence (LaFontana \& Cillessen, 2010). In schools and classrooms, educational aspirations will generally be relatively homogeneous, due to initial sorting of students based on parental socioeconomic status or due to tracked school systems in some countries. These tendencies have been documented in much research on school culture and peer effects that utilised 
classroom-level aggregates to show similarity within and differences between classrooms (e.g. Legewie \& DiPrete, 2012). There is, however, reason to assume that this overall similarity between classes is not the entire story, but that there is additional variation within classes, that coincides with interaction structures.

Goal orientations and educational aspirations can be understood as cultural traits. Culture generally exists within a specific, local context and refers to shared attitudes, values, goals, and practices among a particular set of people. Who exactly comprises this set of people, however, has been debated in past research, and it has been proposed that frequent interactions between them are needed in order to pass on and reinforce particular norms and values that are part of culture (Fine \& Kleinman, 1979). This interactionist view on the diffusion of culture has led to the proposal that social networks should be analysed together with cultural content, to account for the extent to which aspects of culture are embedded in society - which ultimately is central to the definition of culture itself (Pachucki \& Breiger, 2010). Thus, the extent to which individuals aspire to a particular educational or occupational outcome is linked to and shaped by aspirations of others around them.

In the school context, this leads to asking to what extent individuals within schools are adhering to general learning culture and the school culture that is generally present in this context (Lynch, Lerner, \& Leventhal, 2012). The classroom itself, however, is a social system in which interactions happen more frequently among certain individuals: They are clustered in their interactions and hence, likely, in cultural traits. This phenomenon, i.e. the uneven spread of cultural practices in a social system, has received a lot of attention in the research on peer cultures, which received evidence on clustering based on a variety of aspects, such as favourite subjects, smoking, sports, or empathy (Raabe, Boda, \& Stadtfeld, 2018; Haas \& Schaefer, 2014; Simpkins, Schaefer, Price, \& Vest, 2013; Wölfer, Cortina, \& Baumert, 2012). Classroom-level aggregates, as they have been used in past research can thus document mainstream learning cultures, whereas measures based on interactions within the classroom can document the existence of peer cultures that are distinct from the mainstream culture.s

There are two main processes that can create and maintain a peer culture that includes educational aspirations: peer selection and peer socialisation. Peer selection refers to the tendency for 
individuals to become friends with those who are similar to them: Pupils who take school seriously and have high educational aspirations will tend to become friends with others, who hold similarly high aspirations for themselves. Peer socialisation $r$ efers to the tendency for individuals to be influenced towards the attitudes and norms of their friends. This can happen for example due to the fact that adolescents have a strong desire to belong and to fit in with their friends: Due to time spent together, individuals are aware of their friends' preferences and values and are likely to converge with them (Osterman, 2000). This interaction with their friends leads to the creation and reinforcement of adolescents' identities (Deaux \& Martin, 2003), which can only prevail if they are accepted by significant others around them (Klein, Spears, \& Reicher, 2007; Noels, Leavitt, \& Clément, 2010). Especially in friendship groups, this can lead to the creation and persistence of peer norms, since the close structure enables effective sanctioning (Durkheim, 1893; Homans \& Merton, 1974), and since adolescents have a fundamental desire to belong and to be accepted among their peers (Baumeister \& Leary, 1995; Parker, 1987).

Research on homophily, i.e. the tendency that friends tend to be the same or similar in various regards (McPherson, Smith-Lovin, \& Cook, 2001), suggests that peer culture is a multi-dimensional concept that includes various aspects which can also interact with individual characteristics. Thus, educational aspirations can be considered to be one trait of a peer culture, although it is unlikely to be the only factor that adolescents consider important. Research on the social identity of ethnic minorities, for example, has shown that their relationship to other members of their group is important for their identity and psychological functioning (Phinney, 1990), which contributes to why intraethnic friendships are a lot more common in comparison to inter-ethnic friendships (Boda \& Néray, 2015; Smith, McFarland, van Tubergen, \& Maas, 2016).

\section{Peer milieus in classrooms}

Subcultures within the classroom are created among individuals who frequently interact with each other. For most adolescents, being with their friends is the most salient aspects of their school life, and friendship groups provide them with a platform for interactions that form the basis for their culture (Corsaro \& Eder, 1990). We thus expect subcultures to exist among peers in the classroom; this "peer 
milieu" is nested within the wider social context, i.e. the school classroom in our instance. The first hypothesis that we are testing in this piece of research is thus:

Hypothesis 1: Educational aspirations are clustered in peer milieus.

We are conceptualising the peer milieu in two ways: as friends and as friendship groups. Friends are those that individuals consider to be their friends. Friendship groups are informal groups within classrooms, whose members are frequently exposed to each other, but who do not necessarily all consider each other as friends. This is in line with research showing that friendships embedded in social groups are more stable, and can thus also exist in the long-term if they are one-sided (Block, 2015). Thus, we include one-sided friendships as well. In other words, friendship group members, as we define them, are tied to each other by at least one individual considering the other one to be a friend.

In differentiating between these two concepts, direct friends and friendship groups, we are measuring slightly different dimensions of the peer milieu of an individual, but which we assume to carry similar implications for the hypothesized mechanisms: selection and socialisation. We thus use the two operationalisations to test for robustness and expect both concepts of the peer milieu to be equally relevant when it comes to clustering of educational aspirations.

Hypothesis 2: The clustering of educational aspirations will be found across different operationalisations of the peer milieu, i.e. on the level of friends and on the level of friendship groups.

It can be expected that classrooms are relatively homogeneous in terms of educational aspirations. Additionally, the classroom is also a part of a wider social system, such as the school, in which interactions are generally more frequent between individuals. Thus, we are furthermore expecting clustering based on the classroom. This between-classroom variation, however, cannot completely account for the within-classroom variation, or in other words the clustering of aspirations within classrooms.

Hypothesis 3: The peer milieu remains important even when we consider the broader contextual effects. 
Although a lot of peer effect research exists that considers characteristics of classmates, this approach neglects interaction structures. While lack of suitable data often renders the explicit consideration of social structures within classrooms impossible, aggregating on the classroom level has identified peer effects on a variety of outcomes, albeit in an implicit manner. The main strength of our analysis is the possibility to directly measure the theoretically relevant dimension of the peer milieu by the utilisation of social network data. We are able to show correlation and clustering of educational aspirations of individuals within a large number of classrooms in three European countries, and can link our findings to previous literature on peer effects in education.

\section{Methods and Data}

\section{Data}

This paper uses waves 1 and 2 from the Children on Immigrants Longitudinal Survey in Four European Countries (CILS4EU) dataset (Kalter et al., 2014; 2015), the first wave was collected in 2010. It is fully standardised, internationally harmonised, and consists of surveys completed by students at age 14-15 (wave 1) and 15-16 (wave 2), their parents, and teachers. Furthermore, it contains network data both on positive ties (friendships) and negative (rejection) ties (Kruse \& Jacob, 2014). In total, there are 15,203 students clustered in 744 classes. We excluded classes with less than 15 students $(\mathrm{n}=115)$ in order to analyse reasonably large networks, leaving 629 classes.

This paper uses the data from individual students, including friendship networks in the classroom, to construct measures for the peer milieu. Since network data from England has to be treated with caution due to technical problems during the data collection, we are focusing on the Dutch, German, and Swedish part of the data.

We are focusing on interactions between individuals, and there is no reason to assume that people relate differently to each other in the three different national contexts; hence, we are expecting the assumed mechanisms to apply similarly in all three countries. Nevertheless, there are some differences across countries that might affect the magnitude of the results. Germany and the Netherlands have a tracked education system, whereas Sweden does not. Since only graduating from 
the higher tracks enable students to attend university in Germany and the Netherlands, it is likely that variation in aspirations on the classroom level is higher in these countries. Furthermore, Germany has a large sector in vocational training and a relatively smaller university sector; hence, it can be expected that fewer youths wish to get a university degree, since there are many other career options available to them. Sweden has the largest tertiary education sector, which makes a university degree an integral part of many career paths available to adolescents. The prevalence of the highest form of aspiration is thus likely to differ between countries, which also can affect effect sizes. Furthermore, since individuals with a migration background have been found to have higher aspirations, composition of the immigrant community, which differs in the three countries, is also likely affecting this dynamic. These points are further discussed in the section on robustness checks.

\section{Variables}

Table 1 shows descriptive statistics of all variables in the full and analytical sample, indicating no substantial differences. We are unable to use multiple imputations to deal with item non-response, since imputation of network data is currently under-developed. To investigate systematic attrition in our sample, we predicted being in the analytical sample by the individual level characteristics which are also included in our analysis; the results can be found in Table A.1 in the Appendix. We see several dimensions that are significantly predicting presence in the analytical sample, yet, the effect sizes are small. Overall, the low effect size together with the descriptive results gives us reason to assume that we do not see systematic attrition in our sample that could bias the results.

$<$ Table 1 here >

Outcome variable: Academic aspirations of the individual

The outcome variable, educational aspirations, is based on the survey item "What is the highest educational qualification you wish to get?". Four answers were possible: no degree, degree below upper secondary school, degree from upper secondary school, and university degree. The CILS4EU data also contains an item on the individual's realistic expectations of his or her educational 
attainment (see codebooks of wave 1 and 2, CILS4EU, 2016a; 2016b). We chose to focus on the idealistic aspirations, since the item on idealistic aspirations is closer to the way we conceptualise aspirations in our study: It affects motivation, goal orientation, and also expresses a particular wish to reach a certain educational level. Realistic expectations, however, are much more likely to be affected by other factors, such as the economic situation of the family. Hence, we expect idealistic aspirations to be more susceptible and changeable by the social reality surrounding individuals.

In Sweden and the Netherlands, there were only a few participants within the lowest two aspiration categories (in Sweden less than 1\%, and in the Netherlands 8\%, in wave 1), so that the lower three categories were merged. In the German part of the data, there was more variation (less than one percent named the lowest category, $27 \%$ named the second lowest, and $39 \%$ the second highest). We ran the analyses with both a binary and an ordered outcome, both returning the same substantial conclusions. To facilitate the interpretation of our overall analysis, we thus also merged the lower three categories for the German part of the data.

Aspirations are generally higher in wave 2 relatively to wave 1. In Sweden, the proportion of adolescents that aspire to attaining a university degree is largest (66\% in wave $1,74 \%$ in wave 2), followed by the Netherlands (56\% and 62\%, respectively), and in Germany the lowest (31\% and 37\%, respectively). Furthermore, as expected, migrants show higher educational aspirations in comparisons to natives; for further information, see Table A.2 in the Appendix. As discussed above, these crosscountry differences are likely related to the size of the tertiary education sectors.

\section{Independent variables: Academic aspirations in the peer milieu}

We measure the peer milieu in two ways, as friends and as friendship groups. For each individual, we compute the peer milieu, i.e. their friends and those in their friendship group, and take the proportion of those who aspire to a university degree. The measure of friends is based on the network survey item "Who are your best friends in the school class?", for which five nominations were possible, and which exists both at wave 1 and 2 . Thus, it is a measure strictly from the perspective of the individual ("ego-centric"), which does not account for relations between their friends. 
Our second measure for capturing the peer milieu represents the friendship groups in the social network of students (for a graphical illustration of a sample network in the used dataset, see Figure 1). Friendship groups were extracted by applying the Hierarchical Clique Clustering Approach (Everett \& Borgatti, 1998) for wave 1 of the CILS4EU data. A clique is defined as a group of people within a larger network, between whom all possible ties exist (Luce \& Perry, 1949). For our case, this would be a group of people in a classroom, who all nominate each other as friends. This, however, usually results in overlapping groups within classrooms, which is not desirable for our purposes, because we want to measure the one most important social context for each individual. The HCCA is a tool for extracting this most important friendship group for each individual.

It starts by identifying cliques, i.e. it determines sub-networks of students, within the full classroom network, who all nominated each other as friends. Following our theoretical considerations on groups and unbalanced friendships, we apply the HCCA to the undirected friendship networks in the classrooms, which determines the most important clique of every network member. Based on a co-clique matrix, in which the entry of a cell $(i, j)$ is the number of students that clique $i$ and clique $j$ have in common, the hierarchical clustering routine in UCINET assigns each clique to a unique cluster. In classrooms with a suboptimal clustering solution, we were unable to compute the friendship group dimension of the peer milieu, and thus excluded those classrooms $(n=38)$ from the analysis. On average, a friendship group consists of 3.7 members.

The measure of academic aspirations in the peer milieu is based on the proportion of people in the peer milieu who have university aspirations, leaving out the individual. Thus, for each student in our data, there exists a measure of the academic aspirations of the other students for both dimensions of the peer milieu: one based on friends, one based on friendship groups. 


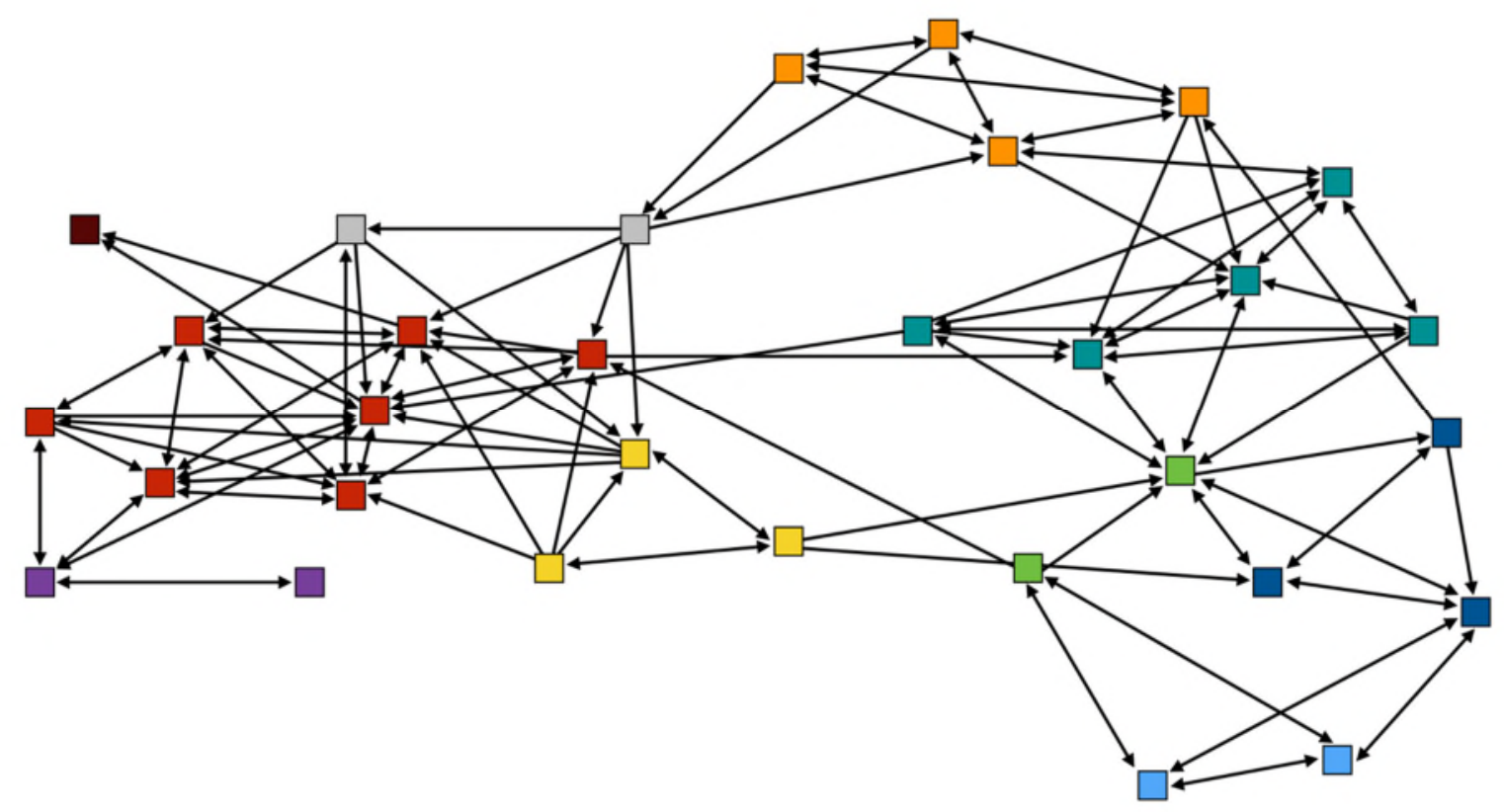

Figure 1. Identified friendship groups based on HCCA in a sample classroom.

To understand the extent to which the two theoretical concepts of the peer milieu actually differ in practice, the overlap of classmates that were captured by the two different measures was calculated. Individuals consider on average $11.8 \%$ friendship group members to not be their friends. Since we include one-sided friendship nominations, this means that group members who were not nominated as friends have nominated the individual in question. Given that only five friendship nominations were possible, this could also be due to the fact that respondents were not able to name all of their friendship group members as friends. Thus, we also consider this overlap only for those who nominated less than five friends, implying that they would have had the space to nominate the other group members as well. With $12.7 \%$, the average percentage of non-friends in the friendship group is even slightly higher for this sub-sample. Analogously, we calculate the proportion of nominated friends who are not in the respective friendship group. On average, this applies to $13.9 \%$ of an individual's friends. These proportions are very similar, and they are in line with the theoretical considerations mentioned above, i.e. that the two measures of the social measures are slightly different, yet likely similar in their conceptual importance for aspirations. 


\section{Independent variables: Academic aspirations in the classroom and migration background}

Based on research showing that the larger context besides peer groups has an effect as well, we are also including academic aspirations in the classroom. To account for the dynamics on the classroom level, net of the dynamics in the peer milieu, we leave out the peer milieu when computing the proportion of students in the classroom who aspire to attaining a university degree. It follows that we have two contextual measures for each individual, one aggregated measure on the classroom level net of the friends and one net of the friendship group of an individual. An individual's own aspirations are also not included in the class-level contextual measure of university aspirations, either.

Migration background is included in the analysis as a dummy variable. We consider those individuals who migrated themselves or who have at least one parent who migrated to have a migration background.

\section{Statistical Analysis}

We use two main types of analyses. First, a first-difference model using individual-level fixed effects predicted the change in individual aspirations by the change of aspirations in the peer milieu, as well as the change in school class aspirations, between waves 1 and 2, to analyse whether and how individuals' aspirations change with the corresponding change in their milieu. We use only the change of aspirations in the peer milieu of explicit friends, since we cannot account for endogenous network processes such as reciprocity and transitivity, which affect the change of the overall network structures between wave 1 and 2. HCCA, the technique to compute our social measure of friendship groups, uses exactly these pieces of information, which is why we focus on directly nominated friends only in this model type. The specification of a first-difference model with individual-level fixed effects only allows for within-individual comparisons, which eliminates omitted variable bias, i.e. unobservable traits across individuals that affect both the predictor and the outcome variables. This is achieved by eliminating all time-invariant observed and unobserved characteristics, i.e. those that do not change across surveys (Allison, 2009). Model 1 of the first-difference model includes only the 
change of aspirations in the peer milieu as an independent variable, and model 2 adds the change of aspirations in the classroom to model 1.

While the first-difference model with individual level fixed effects has a lot of power in analysing change, it cannot account for between-group variance in the overall data and thus cannot explain initial sorting and clustering. We thus include two sets of logistic regression models, predicting university aspirations at wave 2 by the peer milieu at wave 1 . We take a longitudinal approach to address the over-time approach that our assumed mechanisms of peer socialisation are taking. One set of models with the peer milieu of friends, and one set of models with the peer milieu of friendship groups. In both sets, we start with a simple model which includes only survey country and sampling stratum besides the main independent variable of interest: the university aspirations of others in the peer milieu. Model 2 then adds all individual and peer milieu-level controls, and Model 3 the contextual-level predictors and controls. We report average marginal effects (Mood, 2010).

All analyses have been carried out in R 3.3.2, using the plm package for the regression analyses.

\section{Control variables}

We include a number of controls in our models. The proportion of migrants in the school is included to control for the sampling stratum, where immigrant-dense schools were over-sampled. We furthermore control for the survey country.

On the individual level, we control for a variety of confounders in relation to academic aspirations, such as socio-economic background, operationalized as a binary measure of whether at least one of the parents has a university degree. In line with the above-discussed Wisconsin Model, we control for parental aspirations, i.e. whether parents want their child to get a university degree or not. We furthermore control for cognitive ability of the individual, to account for the possibility that ability affects both aspirations and motivation, which could introduce a spurious effect on aspiration. This control is based on a language-free test that requires to solve graphical (pattern) problems in a given time (CILS4EU, 2014). Since cognitive ability depends to a large extent on parental background (e.g. Heckman, 2006), this is also likely to pick up further effects related to socio- 
economic background. We moreover control for gender (based on self-reports) as well as age in months at the time of the survey.

On the level of the peer milieu, we control for the proportion of others with at least one parent that has a university degree, the proportion of native others, as well as the cognitive ability of others. We focus on natives among the explicit friends as well as in the friendship group instead of those with a migration background, since this category includes a variety of different ethnic groups, and can thus refer to varying compositions in different instances. In line with how we compute educational aspirations in the peer milieu, we also calculate this as the mean, leaving out the individual.

Correspondingly, we control for the same factors on the contextual level, while also leaving out the individual and the peer milieu in the computation. By including proportion of natives, average cognitive ability, and proportion of students with a parental university degree of others on the contextual level, we aim to account for sorting into classrooms, which will likely explain clustering of educational aspirations on the class level as well.

\section{Results}

\section{Descriptive results}

Considering the change in aspirations by migration background, we see no differences between natives and ethnic students. Of all native students, $18 \%$ report different aspirations in wave 2 in comparison to wave 1 . For ethnic students, $17 \%$ change their aspirations between wave 1 and 2 . The direction of change is also very similar: $64 \%$ of all change of ethnic students is upwards; for natives, it is $65 \%$ of all change.

Although we are not explicitly focusing on the difference between inter- and intra-ethnic friendships in our analysis, we do consider the proportion of natives among the best friends and in the friendship group: overall, migrants have substantially fewer natives in their peer milieu. For the proportion of native friends among the best friends, there is not much difference between the two waves. In wave 1, natives have on average $76 \%$, and in wave $277 \%$ natives among their best friends. Ethnic students have on average $41 \%$ natives among their best friends, in both waves. The proportion 
of natives among others in the friendship group (measured only at wave 1) is slightly different, but still points to the same tendency. For natives, $73 \%$ of others in the friendship group are also natives, whereas ethnics have on average $44 \%$ natives in their friendship group.

\section{Results from regression analyses}

Table 2 shows the results from the first-difference models with individual-level fixed effects, predicting change in individual academic aspirations by change in the predictor variables. Tables 3 and 4 show the results from the logistic regression models predicting individual university aspirations at wave 2, considering the friends and the friendship group, respectively.

$<$ Table 2 to 4 here $>$

Hypothesis 1, stating that educational aspirations are clustered in peer milieus, is supported. The logistic regression models show clustering in the peer milieu beyond individual characteristics. This applies equally to both dimensions of peer milieu: both the models focusing on friends and the models focusing on friendship groups show the same substantive results, with even the coefficients being similar. In addition, the first difference models show that change in the aspirations of the peer milieu has an effect, whereas change in the aspirations on the classroom level does not. It is important to note that we find these effects while controlling for a rich degree of relevant variables.

Our second hypothesis, stating that there is no substantial difference in the clustering of educational aspirations on the level of friends and on the level of the friendship group, is supported. The differences in the coefficients are small; while in the simple model friends' aspirations have an average marginal effect of 0.49 on individual aspirations, and average aspirations in the friendship group has one of 0.39 , the effect sizes converge to virtually the same coefficient in Models 3 and 4.

Hypothesis 3, stating that the peer milieu remains important even when we consider contextual effects, is supported. Contextual effects on the class-level are important dimensions in which academic aspirations cluster. This is visible in the effect sizes and significance levels of the predictors in the model, as well as in the decreasing effect sizes of the aspirations in the peer milieu. The fact 
that the effect size of academic aspirations on the class-level is twice as high indicates substantial baseline clustering on the class-level. At the same time, other contextual characteristics, such as average cognitive ability and parental degree on the class-level are not significant, while they are on the level of the peer milieu. Nevertheless, the peer milieu, both as in friends and as in friendship groups, remains significant with a relatively strong effect size upon introduction of class-level characteristics. An even stronger tendency can be seen in the first-difference model, which indicates that individuals change their aspirations more in line with their peer milieu than with their classrooms.

\section{Robustness Checks}

We ran the analyses on different sub-samples of the full data: we tested our hypotheses separately for each survey country, and ran the analyses by school track in Germany and the Netherlands. The country-level analyses showed some differences: The results are strongest for the Swedish subsample. For the German and Dutch sub-sample, in neither version of the peer milieu, does the classroom context have a significant effect on individual university aspirations. In the fixed effects models, the country-based analyses for Germany and Sweden show the same substantive results as the pooled analysis; for the Netherlands, the change variables are non-significant. The analysis by school track did not show any additional differences.

There are several reasons why we detect these differences across countries. First, this could be due to lower statistical power in the German and in the Dutch data, since more cases are lost in comparison to the Swedish data. Second, it could be due to the fact that in Germany and in the Netherlands the educational system is tracked, resulting in fewer differences in aspirations on the class-level: Only students graduating from the highest tracks are typically eligible for university studies (although there are routes back to the academic track). Third, as mentioned above, the size of the tertiary education sector is much larger in Sweden. Fourth, as countries differ in their immigrant population and migrants tend to have higher aspirations in comparison to natives from a similar socioeconomic background, this could affect the magnitude of these results. Since peer cultures can feature many cultural traits, it could be the case that educational aspirations are a comparably less important cultural trait of migrant's peer cultures than others that more directly related to upholding 
their ethnic identity. The extent to which is the case depends on a variety of factors, such as group size and or even the particular minority group in question. While this is beyond the scope of this paper, we have carried out some explorative analyses regarding this aspect, which point to the tendency that for those with a migration background, friends' aspirations matter less. These analyses are described and discussed further in section $\mathrm{A}$ in the appendix.

Furthermore, we carried out all analyses with multinomial logistic regressions and an ordered outcome variable for the German part of the data. Even though the distribution of the original variable was skewed more in the other two countries, we did the same for the Dutch and the Swedish part of the data. We furthermore checked robustness through different variable operationalisations. We used language ability instead of cognitive ability, and used the mode instead of the mean university aspirations in the peer milieu and the classroom. All of these robustness checks resulted in the same substantive conclusions. While we did observe country-differences regarding the magnitude of the effects, the pooled analysis, using country-weights, finds overall evidence for clustering of aspirations within classrooms. Thus, we are confident that we find overall support for our assumed mechanisms.

\section{Discussion and conclusion}

Our study finds evidence that educational aspirations are socially embedded in peer cultures: Clustering and homophily regarding educational aspirations is present on a level between the individual and the school class, namely the peer level, or on the level of the peer milieu, as we term it in this study. Since adolescents have a fundamental need to belong and to fit in with their friends, they matter for shaping their educational aspirations, stabilising them towards the aspirational attitude that prevails in peer clusters. With our study, we add to the research on educational aspirations, which was not, to our knowledge, studied through considering social network data.

These findings illustrate the existence of dynamics on the peer level, that happen besides classroom level contextual effects. Since we are considering both levels, we can show that while there is a separate effect of those in the class who are not in an individual's peer milieu, peer cultures seem to play a role as well. Studies on peer cultures and effects in classrooms often assume mechanisms at the interpersonal level, such as peer selection and peer socialisation, but often have to refer to 
classroom-level aggregates due to lack of suitable data. Since we are considering the interaction structure through friendship networks, we can measure clustering of educational aspirations at exactly this interpersonal level. When data on interactions within the classroom is available, it is thus worth to consider the peer milieu, too. The tendencies identified in this study could even be more pronounced for other cultural traits, such as cultural tastes or political attitudes. Thus, our results have implication for school policies and for testing their effectiveness.

There are some limitations in our study. Our finding of homophily in educational aspirations among friends and friendship groups can come about through two mechanisms: the educational aspirations of one influencing the aspirations of another (peer influence), and students befriending those with the same aspiration (peer selection). While longitudinal social network models are able to disentangle those effects (Steglich, Snijders, \& Pearson, 2010), these analyses are comparatively less available and accessible, which can be explained by computationally demanding analyses, strict data requirements, and interpretations that are different from those of usual regression analyses.

Furthermore, we assume that clustering of educational aspirations is a sign for peer cultures that include this as a cultural trait. This, however, does not necessarily have to apply, since based on our analyses we do not know how salient educational aspirations are in the respective peer cultures. Aspirations could correlate with other traits, which are actually the ones that adolescents cluster by. Additionally, we are only able to account for peer cultures within the classroom. While this is a reasonable approach since adolescents spend most of their waking hours in school, there are other relevant peer cultures outside the classroom, including individuals that are not in the same classroom, for example based on sports or music.

A strength of our analysis is the use of two conceptualisations of the peer milieu, which increases the robustness of results. We did not expect differences in these dimensions of clustering, and indeed, many of the coefficients are almost identical, and both analyses yield the same conclusions. Considering that the construction of friendship groups using the HCCA is timeconsuming and computationally elaborate, this means that a friendship group construction like this is not always necessary. Further tests should be carried out to support this, but the similarity of the results suggests that the utilisation of friends is likely to be sufficient. Including friends and their 
characteristics in analyses is relatively straightforward and seems to be able to accurately capture the peer milieu, which has received much theoretical, but little empirical attention. Future studies can further deepen our understanding in this regard, which requires the collection of more large-scale social network data, since availability is still scarce.

In conclusion, our study reveals that educational aspirations are embedded in peer clusters within classrooms. We furthermore find initial evidence of different dynamics for ethnic minorities this, however, has to be explored in future research. By accounting for the immediate social surrounding in our analysis through the utilisation of social network data, we show the promise of identifying a peer milieu on the basis of friendship networks within the class-room level, as well as the potential to follow up on our results with more elaborate techniques of social network analysis. 


\section{Bibliography}

Allison, P. D. (2009). Fixed effects regression models. London: SAGE.

Baumeister, R. F., \& Leary, M. R. (1995). The need to belong: desire for interpersonal attachments as a fundamental human motivation. Psychological Bulletin, 117(3), 497-529.

Block, P. (2015). Reciprocity, transitivity, and the mysterious three-cycle. Social Networks, 40, 163173. http://doi.org/10.1016/j.socnet.2014.10.005

Boda, Z., \& Néray, B. (2015). Inter-ethnic friendship and negative ties in secondary school. Social Networks, 43, 57-72. http://doi.org/10.1016/j.socnet.2015.03.004

Boudon, R. (1974). Education, opportunity, and social inequality : changing prospects in Western society. New York: Wiley.

Brechwald, W. A., \& Prinstein, M. J. (2011). Beyond Homophily: A Decade of Advances in Understanding Peer Influence Processes. Journal of Research on Adolescence, 21(1), 166-179. http://doi.org/10.1111/j.1532-7795.2010.00721.x

Brinbaum, Y., \& Cebolla-Boado, H. (2007). The school careers of ethnic minority youth in France: Success or disillusion? Ethnicities, 7(3), 445-474. http://doi.org/10.1177/1468796807080237

CILS4EU. (2014). Children of Immigrants Longitudinal Survey in Four European Countries. Technical Report. Wave 1 -2010/2011, v1.1.0. Mannheim: Mannheim University.

CILS4EU. (2016a). Children of Immigrants Longitudinal Survey in Four European Countries. Codebook. Wave 1 - 2010/2011, v1.2.0. Mannheim: Mannheim University.

CILS4EU. (2016b). Children of Immigrants Longitudinal Survey in Four European Countries. Codebook. Wave 2 - 2011/2012, v2.3.0 (pp. 1-456). Mannheim: Mannheim University.

Corsaro, W. A., \& Eder, D. (1990). Children's Peer Cultures. Annual Review of Sociology, 16, 197-220. http://doi.org/10.2307/2083268?refreqid=searchgateway:18aa13447a3bfd66b65c8fea9c4f4236

Deaux, K., \& Martin, D. (2003). Interpersonal networks and social categories: Specifying levels of context in identity processes. American Sociological Review, 66(2), 101-117. http://doi.org/10.2307/1519842

Durkheim, É. (1893). De la division du travail social: étude sur l'organisation des sociétés supérieures. New York: Free Press.

Dustmann, C., \& Frattini, T. (2012). Immigration: The European Experience. NORFACE Migration Discussion Paper, 01. http://doi.org/10.2139/ssrn.2023575

Erikson, R., \& Jonsson, J. O. (Eds.). (1996). Can education be equalized? Boulder: Westview Press.

Everett, M. G., \& Borgatti, S. P. (1998). Analyzing clique overlap. Connections.

Feliciano, C., \& Rumbaut, R. G. (2005). Gendered paths: Educational and occupational expectations and outcomes among adult children of immigrants. Ethnic and Racial Studies, 28(6), 1087-1118. http://doi.org/10.1080/01419870500224406

Fine, G. A., \& Kleinman, S. (1979). Rethinking Subculture: An Interactionist Analysis. American Journal of Sociology, 85(1), 1-20. http://doi.org/10.2307/2778065?refreqid=searchgateway:f75207ac075b6856655734cedb5f7428

Haas, S. A., \& Schaefer, D. R. (2014). With a Little Help from My Friends? Asymmetrical Social Influence on Adolescent Smoking Initiation and Cessation. Journal of Health and Social Behavior, 55(2), 126-143. http://doi.org/10.1177/0022146514532817

Heath, A. F., Rothon, C., \& Kilpi, E. (2008). The Second Generation in Western Europe: Education, Unemployment, and Occupational Attainment. Annual Review of Sociology, 34(1), 211-235. http://doi.org/10.1146/annurev.soc.34.040507.134728

Heckman, J. J. (2006). Skill formation and the economics of investing in disadvantaged children. Science.

Homans, G. C., \& Merton, R. K. (1974). Social behavior : its elementary forms. New York: Harcourt Brace Jovanovich, Inc.

Jackson, M. (Ed.). (2013). Determined to Succeed? Stanford, California: Stanford University Press. http://doi.org/10.11126/stanford/9780804783026.001.0001 
Jackson, M., Jonsson, J. O., \& Rudolphi, F. (2012). Ethnic Inequality in Choice-driven Education Systems: A Longitudinal Study of Performance and Choice in England and Sweden. Sociology of Education, 85(2), 158-178. http://doi.org/10.1177/0038040711427311

Jonsson, J. O., \& Rudolphi, F. (2011). Weak Performance--Strong Determination: School Achievement and Educational Choice among Children of Immigrants in Sweden. European Sociological Review, 27(4), 487-508. http://doi.org/10.1093/esr/jcq021

Kalter, F., Heath, A., Hewstone, M., Jonsson, J. O., Kalmijn, M., Kogan, I., \& Tubergen, F. V. (2014). Children of Immigrants Longitudinal Survey in Four European Countries (CILS4EU). http://doi.org/doi:10.4232/cils4eu.5353.1.1.0

Kalter, F., Heath, A., Hewstone, M., Jonsson, J. O., Kalmijn, M., Kogan, I., \& Tubergen, F. V. (2015). Children of Immigrants Longitudinal Survey in Four European Countries (CILS4EU). http://doi.org/10.4232/cils4eu.5353.2.1.0

Klein, O., Spears, R., \& Reicher, S. (2007). Social Identity Performance: Extending the Strategic Side of SIDE. Personality and Social Psychology Review, 11(1), 28-45. http://doi.org/10.1177/1088868306294588

Kruse, H., \& Jacob, K. (2014). Sociometric Fieldwork Report Children of Immigrants Longitudinal Survey in 4 European Countries, 1-11.

LaFontana, K. M., \& Cillessen, A. H. N. (2010). Developmental Changes in the Priority of Perceived Status in Childhood and Adolescence. Social Development, 19(1), 130-147. http://doi.org/10.1111/j.1467-9507.2008.00522.x

Legewie, J., \& DiPrete, T. A. (2012). School Context and the Gender Gap in Educational Achievement. American Sociological Review, 77(3), 463-485. http://doi.org/10.1177/0003122412440802

Lomi, A., Snijders, T. A. B., Steglich, C. E. G., \& Torló, V. J. (2011). Why are some more peer than others? Evidence from a longitudinal study of social networks and individual academic performance. Social Science Research, 40, 1506-1520. http://doi.org/10.1016/j.ssresearch.2011.06.010

Luce, R. D., \& Perry, A. D. (1949). A method of matrix analysis of group structure. Psychometrika, 14(2), 95-116. http://doi.org/10.1007/BF02289146

Lynch, A. D., Lerner, R. M., \& Leventhal, T. (2012). Adolescent Academic Achievement and School Engagement: An Examination of the Role of School-Wide Peer Culture. Journal of Youth and Adolescence, 42(1), 6-19. http://doi.org/10.1007/s10964-012-9833-0

McPherson, M., Smith-Lovin, L., \& Cook, J. M. (2001). Birds of a Feather: Homophily in Social Networks. Annual Review of Sociology, 27, 415-444. http://doi.org/10.2307/2678628?ref=search-gateway:e197b0dab973a7aab7252ea2b29dacbb Mood, C. (2010). Logistic Regression: Why We Cannot Do What We Think We Can Do, and What We Can Do About It. European Sociological Review, 26(1), 67-82. http://doi.org/10.1093/esr/jcp006

Noels, K. A., Leavitt, P. A., \& Clément, R. (2010). "To See Ourselves as Others See Us": On the Implications of Reflected Appraisals for Ethnic Identity and Discrimination. Journal of Social Issues, 66(4), 740-758. http://doi.org/10.1111/j.1540-4560.2010.01673.x

Osterman, K. F. (2000). Students' need for belonging in the school community. Review of Educational Research.

Pachucki, M. A., \& Breiger, R. L. (2010). Cultural Holes: Beyond Relationality in Social Networks and Culture. Annual Review of Sociology, 36(1), 205-224. http://doi.org/10.1146/annurev.soc.012809.102615

Parker, J. G. (1987). Peer relations and later personal adjustment: Are low-accepted children at risk? Psychological Bulletin, 102(3), 357-389.

Phinney, J. S. (1990). Ethnic identity in adolescents and adults: review of research. Psychological Bulletin, 108(3), 499-514.

Portes, A., Aparicio, R., Haller, W., \& Vickstrom, E. (2010). Moving Ahead in Madrid: Aspirations and Expectations in the Spanish Second Generation. The International Migration Review, 44(4), 767- 
801. http://doi.org/10.2307/40930951?ref=searchgateway:b0d66d80f525ad8c4329b910d18354ab

Raabe, I. J., Boda, Z., \& Stadtfeld, C. (2018). The social pipeline: How friend influence and peer exposure widen the STEM gender gap. Sociology of Education, forthcoming.

Rjosk, C., Richter, D., Hochweber, J., Lüdtke, O., Klieme, E., \& Stanat, P. (2014). Socioeconomic and language minority classroom composition and individual reading achievement: The mediating role of instructional quality. Learning and Instruction, 32, 63-72.

http://doi.org/10.1016/j.learninstruc.2014.01.007

Sewell, W. H., Haller, A. O., \& Portes, A. (1969). The educational and early occupational attainment process. American Sociological Review, 34(1), 82. http://doi.org/10.2307/2092789

Sherif, M., \& Sherif, C. W. (1964). Reference Groups. Chicago: Regnery.

Simpkins, S. D., Schaefer, D. R., Price, C. D., \& Vest, A. E. (2013). Adolescent Friendships, BMI, and Physical Activity: Untangling Selection and Influence Through Longitudinal Social Network Analysis. Journal of Research on Adolescence, 23(3), 537-549. http://doi.org/10.1111/j.15327795.2012.00836.x

Smith, S., McFarland, D. A., van Tubergen, F., \& Maas, I. (2016). Ethnic Composition and Friendship Segregation: Differential Effects for Adolescent Natives and Immigrants 1. American Journal of Sociology, 121(4), 1223-1272. http://doi.org/10.1086/684032

Steglich, C., Snijders, T. A. B., \& Pearson, M. (2010). Dynamic networks and behaviour: separating selection from influence. Sociological Methodology, 40, 329-393.

http://doi.org/10.2307/41336888?ref=search-gateway:8bb54955d81f2badd85db7137d601b32

van Ewijk, R., \& Sleegers, P. (2010). Peer ethnicity and achievement: a meta-analysis into the compositional effect. School Effectiveness and School Improvement, 21(3), 237-265. http://doi.org/10.1080/09243451003612671

Wölfer, R., Cortina, K. S., \& Baumert, J. (2012). Embeddedness and empathy: How the social network shapes adolescents' social understanding. Journal of Adolescence, 35(5), 1295-1305. http://doi.org/10.1016/j.adolescence.2012.04.015

Youniss, J., \& Smollar, J. (1985). Adolescent relations with mothers, fathers, and friends. Chicago: University of Chicago Press. 
Table 1. Descriptive statistics of variables of full and analytical sample.

\begin{tabular}{|c|c|c|c|c|c|c|c|c|c|c|c|c|}
\hline & \multicolumn{6}{|c|}{ Full sample } & \multicolumn{6}{|c|}{ Analytical sample } \\
\hline & Mean & SD & Median & Min & Max & $\mathrm{N}$ & Mean & SD & Median & Min & Max & $\mathrm{N}$ \\
\hline Individual university aspirations, w1 & 0.51 & 0.50 & 1.00 & 0.00 & 1.00 & 14,314 & 0.55 & 0.5 & 1.00 & 0.00 & 1.00 & 7,147 \\
\hline Individual university aspirations, w2 & 0.58 & 0.49 & 1.00 & 0.00 & 1.00 & 12,374 & 0.62 & 0.48 & 1.00 & 0.00 & 1.00 & 7,147 \\
\hline Age (in months) & 179.91 & 7.59 & 179.001 & 57.00 & 228.00 & 14,342 & 178.76 & 6.75 & 178.00 & 158.00 & 219.00 & 7,147 \\
\hline Cognitive ability index & 18.57 & 4.46 & 19.00 & 0.00 & 27.00 & 13,984 & 19.16 & 4.16 & 20.00 & 0.00 & 27.00 & 7,147 \\
\hline At least one parent has a university degree & 0.25 & 0.43 & 0.00 & 0.00 & 1.00 & 15,203 & 0.29 & 0.45 & 0.00 & 0.00 & 1.00 & 7,147 \\
\hline Parental university aspirations & 0.38 & 0.48 & 0.00 & 0.00 & 1.00 & 14,300 & 0.41 & 0.49 & 0.00 & 0.00 & 1.00 & 7,147 \\
\hline Friends: av. university aspirations, w1 & 0.51 & 0.36 & 0.50 & 0.00 & 1.00 & 13,417 & 0.55 & 0.34 & 0.60 & 0.00 & 1.00 & 7,147 \\
\hline Friends: av. university aspirations, w2 & 0.62 & 0.36 & 0.67 & 0.00 & 1.00 & 9,874 & 0.63 & 0.36 & 0.67 & 0.00 & 1.00 & 7,147 \\
\hline Friends: av. cognitive ability & 18.69 & 3.18 & 19.00 & 0.00 & 27.00 & 13,375 & 19.02 & 3.00 & 19.40 & 1.00 & 26.5 & 7,147 \\
\hline Friends: prop. with parental degree & 0.25 & 0.28 & 0.20 & 0.00 & 1.00 & 13,460 & 0.28 & 0.29 & 0.20 & 0.00 & 1.00 & 7,147 \\
\hline Friends: prop. natives & 0.63 & 0.36 & 0.75 & 0.00 & 1.00 & 13,424 & 0.66 & 0.35 & 0.75 & 0.00 & 1.00 & 7,147 \\
\hline Friendship group: av. university aspirations & 0.50 & 0.35 & 0.40 & 0.00 & 1.00 & 13,862 & 0.54 & 0.38 & 0.50 & 0.00 & 1.00 & 7,147 \\
\hline Friendship group: prop. with parental degree & 0.25 & 0.30 & 0.17 & 0.00 & 1.00 & 13,878 & 0.29 & 0.33 & 0.20 & 0.00 & 1.00 & 7,147 \\
\hline Friendship group: av. cognitive ability & 18.5 & 3.10 & 18.00 & 0.00 & 27.00 & 13,835 & 19 & 3.32 & 19.33 & 1.00 & 27.00 & 7,147 \\
\hline Friendship group: prop. natives & 0.62 & 0.35 & 0.56 & 0.00 & 1.00 & 13,878 & 0.66 & 0.38 & 0.75 & 0.00 & 1.00 & 7,147 \\
\hline Class: av. university aspirations (- friends), w1 & 0.38 & 0.21 & 0.39 & 0.00 & 0.94 & 14,314 & 0.4 & 0.19 & 0.41 & 0.00 & 0.93 & 7,147 \\
\hline Class: av. university aspirations (- friends), w2 & 0.39 & 0.20 & 0.41 & -0.20 & 0.95 & 12,374 & 0.41 & 0.18 & 0.42 & -0.06 & 0.95 & 7,147 \\
\hline Class: prop. with parental degree (- friends) & 0.20 & 0.16 & 0.17 & 0.00 & 0.83 & 15,203 & 0.21 & 0.15 & 0.18 & 0.00 & 0.81 & 7,147 \\
\hline Class: av. cognitive ability (- friends) & 13.44 & 2.97 & 13.58 & 0.00 & 22.56 & 13,984 & 13.65 & 2.63 & 13.67 & 5.44 & 21.58 & 7,147 \\
\hline Class: prop. native students (- friends) & 0.69 & 0.22 & 0.75 & 0.04 & 1.20 & 14,420 & 0.74 & 0.20 & 0.79 & 0.07 & 1.06 & 7,147 \\
\hline Class: av. university aspirations (- fr.group) & 0.53 & 0.26 & 0.56 & 0.00 & 1.00 & 13,390 & 0.54 & 0.25 & 0.57 & 0.00 & 1.00 & 7,147 \\
\hline Class: av. cognitive ability (- fr.group) & 18.71 & 2.31 & 18.83 & 8.17 & 23.85 & 13,367 & 18.85 & 2.30 & 18.94 & 8.17 & 23.85 & 7,147 \\
\hline Class: prop. with parental degree (- fr.group) & 0.26 & 0.19 & 0.22 & 0.00 & 0.94 & 13,390 & 0.26 & 0.19 & 0.24 & 0.00 & 0.94 & 7,147 \\
\hline Class: prop. native students (- fr.group) & 0.64 & 0.26 & 0.71 & 0.00 & 1.00 & 13,390 & 0.65 & 0.26 & 0.73 & 0.00 & 1.00 & 7,147 \\
\hline Country: Germany & & & & & & 5,127 & & & & & & 2,235 \\
\hline Country: The Netherlands & & & & & & 4,628 & & & & & & 2,101 \\
\hline Country: Sweden & & & & & & 5,448 & & & & & & 2,811 \\
\hline Gender: male & & & & & & 7,192 & & & & & & 3,463 \\
\hline Gender: female & & & & & & 7,204 & & & & & & 3,684 \\
\hline Migration background: native & & & & & & 8,991 & & & & & & 4,729 \\
\hline Migration background: non-native & & & & & & 5,429 & & & & & & 2,418 \\
\hline
\end{tabular}


Table 2. First-difference models with individual-level fixed effects, predicting change in individual university aspirations between wave 1 and 2 (Models 1 and 2).

Model 1

\begin{tabular}{lll}
\hline & & \\
Change of aspirations of friends & $0.08^{* * *}$ & $0.08^{* * *}$ \\
& $(0.02)$ & $(0.02)$ \\
Change of aspirations of class & & 0.02 \\
& & $0.04)$ \\
Intercept & $0.06^{* * *}$ & $0.06^{* * *}$ \\
& $(0.01)$ & $0.01)$ \\
\hline $\mathrm{R}^{2}$ & & \\
Adj. $\mathrm{R}^{2}$ & 0.00 & 0.00 \\
Num. obs. & 0.00 & 0.00 \\
& 7172 & 7172 \\
\hline
\end{tabular}

${ }^{* * *} \mathrm{p}<0.001,{ }^{* *} \mathrm{p}<0.01,{ }^{*} \mathrm{p}<0.05$

Notes: Class-room level average aspirations were computed leaving out individual aspirations as well as friends' aspirations. 
Table 3. Logistic regression predicting individual university aspirations at wave 2 (reporting average marginal effects, standard errors clustered on class level).

\begin{tabular}{|c|c|c|c|}
\hline & Model 1 & Model 2 & Model 3 \\
\hline Friends: av. university aspirations & $\begin{array}{l}0.49^{* * *} \\
(0.02)\end{array}$ & $\begin{array}{l}0.18^{* * *} \\
(0.02)\end{array}$ & $\begin{array}{l}0.12^{* * *} \\
(0.02)\end{array}$ \\
\hline Individual university aspirations, w1 & & $\begin{array}{l}0.39 * * * \\
(0.01)\end{array}$ & $\begin{array}{l}0.38^{* * *} \\
(0.01)\end{array}$ \\
\hline Sex (female) & & $\begin{array}{l}0.06^{* * *} \\
(0.01)\end{array}$ & $\begin{array}{l}0.06^{* * *} \\
(0.01)\end{array}$ \\
\hline Age (in months) & & $\begin{array}{l}-0.01^{* * *} \\
(0.00)\end{array}$ & $\begin{array}{l}-0.00^{* * *} \\
(0.00)\end{array}$ \\
\hline Migration background (binary) & & $\begin{array}{l}0.09^{* * *} \\
(0.02)\end{array}$ & $\begin{array}{l}0.09 \text { *** } \\
(0.02)\end{array}$ \\
\hline Cognitive ability index & & $\begin{array}{l}0.01^{* * *} \\
(0.00)\end{array}$ & $\begin{array}{l}0.01^{* * *} \\
(0.00)\end{array}$ \\
\hline At least one parent has a university degree & & $\begin{array}{l}0.07^{* * *} \\
(0.02)\end{array}$ & $\begin{array}{l}0.06^{* * *} \\
(0.02)\end{array}$ \\
\hline Parental university aspirations & & $\begin{array}{l}0.16^{* * *} \\
(0.02)\end{array}$ & $\begin{array}{l}0.15^{* * *} \\
(0.02)\end{array}$ \\
\hline Friends: av. cognitive ability & & $\begin{array}{l}-0.05 \\
(0.03)\end{array}$ & $\begin{array}{l}-0.05 \\
(0.03)\end{array}$ \\
\hline Friendship group: prop. natives & & $\begin{array}{l}0.01^{* * *} \\
(0.00)\end{array}$ & $\begin{array}{l}0.01^{* *} \\
(0.00)\end{array}$ \\
\hline Friendship group: prop. with parental degree & & $\begin{array}{l}0.14^{* * *} \\
(0.03)\end{array}$ & $\begin{array}{l}0.13^{* * *} \\
(0.03)\end{array}$ \\
\hline Class: av. university aspirations (- friends) & & & $\begin{array}{l}0.35^{* * *} \\
(0.06)\end{array}$ \\
\hline Class: prop. native students (- friends) & & & $\begin{array}{l}0.09 \\
(0.06)\end{array}$ \\
\hline Class: av. cognitive ability (- friends) & & & $\begin{array}{l}-0.00 \\
(0.00)\end{array}$ \\
\hline Class: prop. with parental degree (- friends) & & & $\begin{array}{l}-0.06 \\
(0.07)\end{array}$ \\
\hline Num. obs. & 7147 & 7147 & 7147 \\
\hline Log Likelihood & -4071.7 & -3191.0 & -3164.9 \\
\hline Deviance & 8143.4 & 6382.1 & 6329.9 \\
\hline AIC & 8153.4 & 6412.1 & 6367.9 \\
\hline BIC & 8187.8 & 6515.2 & 6498.6 \\
\hline
\end{tabular}

*** $\mathrm{p}<0.001,{ }^{* *} \mathrm{p}<0.01,{ }^{*} \mathrm{p}<0.05$

Notes: Class-room level averages were computed leaving out the individual as well as friends. All predictor variables are based on measures from wave 1. Models control for sampling stratum and country. Abbreviation: prop = proportion, av. = average, migr.b. = migration background. 
Table 4. Logistic regression predicting individual university aspirations at wave 2 (reporting average marginal effects, standard errors clustered on class level).

Model 1 Model 2 Model 3

Friendship group: av. university aspirations

$0.39^{* * *} \quad 0.17^{* * *} \quad 0.12^{* * *}$

Individual university aspirations, w1

(0.02) (0.02) (0.02)

$0.39 * * * \quad 0.38^{* * *}$

Sex (female)

(0.01) (0.01)

Sex (female)

Age (in months)

$0.06^{* * *} \quad 0.06^{* * *}$

(0.01) (0.01)

Migration background (binary)

$-0.01^{* * *} \quad-0.00^{* * *}$

$(0.00) \quad(0.00)$

Cognitive ability index

(0.02) (0.02)

$0.01^{* * *} \quad 0.01^{* * *}$

$(0.00) \quad(0.00)$

At least one parent has a university degree

$0.07^{* * *} \quad 0.06^{* * *}$

Parental university aspirations

(0.02) (0.02)

$0.16^{* * *} \quad 0.15^{* * *}$

(0.02) (0.02)

Friendship group: prop. natives

$0.01^{* * *} \quad 0.01^{* * *}$

(0.00) (0.00)

Friendship group: av. cognitive ability

$0.08^{* *} \quad 0.06^{*}$

(0.02) (0.02)

Friendship group: prop. with parental degree

Class: av. university aspirations (- fr.group)

Class: prop. native students (- fr.group)

Class: av. cognitive ability (- fr.group)

$-0.00$

$(0.00)$

Class: prop. with parental degree (- fr.group)

\begin{tabular}{llll}
\hline Num. obs. & 7147 & 7147 & 7147 \\
Log Likelihood & -4128.7 & -3196.9 & -3169.6 \\
Deviance & 8257.3 & 6393.7 & 6339.3 \\
AIC & 8267.3 & 6421.7 & 6377.3 \\
BIC & 8301.7 & 6517.9 & 6507.9 \\
\hline
\end{tabular}

${ }^{* * *} \mathrm{p}<0.001,{ }^{* *} \mathrm{p}<0.01,{ }^{*} \mathrm{p}<0.05$

Notes: Clique-level averages were computed leaving out the individual. Class-room level averages were computed with leaving out the individual as well as the clique. All predictor variables are based on measures from wave 1. Models control for sampling stratum and survey country. Abbreviations: prop = proportion, av. = average, fr.group = friendship group, migr.b. = migration background. 


\title{
What is going on around you: Peer milieus and educational aspirations
}

\author{
Isabel J. Raabe and Ralf Wölfer
}

Table A.1. Logistic regression predicting being in the analytical sample (vs. missing information on a crucial variable), reporting average marginal effects.

\begin{tabular}{ll} 
the Netherlands (ref. Germany) & $0.08^{* *}$ \\
Sweden (ref. Germany) & $(0.03)$ \\
& $0.13^{* * *}$ \\
Individual university aspirations wave 1 & $(0.03)$ \\
& 0.02 \\
Individual university aspirations wave 2 & $(0.01)$ \\
& $0.05^{* * *}$ \\
Sex (female) & $(0.01)$ \\
& 0.02 \\
Age (in months) & $(0.01)$ \\
& $-0.00^{* * *}$ \\
Migration background (binary) & $(0.00)$ \\
& $-0.03^{*}$ \\
Cognitive ability index & $(0.01)$ \\
& $0.01^{* * *}$ \\
At least one parent has a university degree & $(0.00)$ \\
Sample stratum & 0.02 \\
BIC & $(0.01)$ \\
Num. obs. & -0.02 \\
Deviance & $(0.01)$ \\
& \\
\hline & 11172 \\
& -6978.09 \\
& 13956.19 \\
& 13978.19 \\
& 14058.72 \\
\hline
\end{tabular}


${ }^{* * *} \mathrm{p}<0.001,{ }^{* *} \mathrm{p}<0.01,{ }^{*} \mathrm{p}<0.05$ 
Table A.2. Proportion of natives and migrants aspiring to a university degree, by country.

\begin{tabular}{llll} 
& & wave 1 & wave 2 \\
\hline \multirow{2}{*}{ Germany } & Natives & & \\
& Migrants & $29.9 \%$ & $34.8 \%$ \\
The Netherlands & & $33.3 \%$ & $40.0 \%$ \\
& Natives & & \\
Migrants & $51.5 \%$ & $58.5 \%$ \\
\multirow{2}{*}{ Sweden } & Natives & $66.8 \%$ & $75.4 \%$ \\
& Migrants & $60.5 \%$ & $70.9 \%$ \\
& & $73.0 \%$ & $80.6 \%$
\end{tabular}




\section{Section A: Clustering of educational aspirations among migrants}

Educational aspirations are likely only one of many cultural traits that are part of a particular peer culture. For students with a migration background in general it could be the case that educational aspirations are less of an important cultural trait of their peer culture in comparison to others, which are more directly related to upholding their ethnic identity. The extent to which is the case depends on a variety of factors, such as group size and or even the particular minority group in question. While this is beyond the scope of this paper, we nevertheless expect peer cultures of minority students to be less oriented towards educational aspirations.

To test this, we add a migration background interaction effect to the logistic regression models, and calculate the individual-level fixed effects model separately for migrants and non-migrants. This is necessary since the migration background is a time-invariant individual trait and thus does not change between waves 1 and 2; thus, we cannot include this in the model as an independent variable as such. Parallel to that, we also calculate the logistic regressions separately for migrants and natives.

We find some evidence for clustering being less pronounced for adolescents with a migration background. In the logistic regressions, we first see the expected positive effect on university aspirations of those with a migration background. They are more likely to aspire to a university degree in comparison to natives and the size of the effect does not change throughout the model buildup. This is the case in the set of models using friends as the peer milieu (Table A.4), as well as in the set of models using friendship groups (Table A.7); furthermore, the coefficients are the same. The interaction effect of average university aspirations of others in the peer milieu and migration background, however, is non-significant with a negligible effect size. Thus, we cannot conclude that clustering based on average university aspirations of the peer milieu varies by migration background. Nevertheless, we do find some evidence that clustering is less pronounced for adolescents with a migration background in the fixed-effect models. Table A.3 show the first-difference analysis on two sub-samples of the data, split up by migration background. As mentioned in the section on descriptive results, proportions and directions of change of aspirations are virtually the same between natives and ethnics. Yet, we see that the significant effect discussed above, signifying that individuals change 
their aspirations with their friends, is only present in the sub-sample of natives. When running the longitudinal hypotheses for subsamples based on migration background (see Tables A.5, A.6, A.7 and A.8), effect sizes of the peer milieu are lower for individuals with a migration background. Thus, although we do not find a significant interaction effect, our results point to the tendency that for those with a migration background, friends' aspirations matter less.

Since our analysis is focusing on detecting the extent of clustering and not on definitely exploring the mechanism leading to this, it remains unclear why migrants are less susceptible to changes in their friends' aspiration than natives. This could indeed be related to other cultural traits related to their ethnic identity being more salient feature of peer cultures among ethnic minorities. Alternatively, it could be a statistical artefact resulting from ethnic minorities generally having higher aspirations and hence less variation. More detailed analyses are needed to further explore this, for example by differentiating between inter- and intra-ethnic connections, by using a finer definition of the ethnic category into countries of origin, migration generation, or measures of segregation and ethnic composition in the classroom. Furthermore, a closer consideration of the institutional settings and their implications in the three countries included in this article is likely a fruitful path in further investigating this alley of research, since they differ in terms of immigration policies, composition of migration population, and how immigrants are integrated in the education system (e.g. Griga \& Hadjar, 2014). 
Table A.3: First-difference models with individual-level fixed effects, predicting change in individual university aspirations between wave 1 and 2; for students with a migration background (Models 1 and 2) and for natives (Models 3 and 4).

\begin{tabular}{lllll} 
& \multicolumn{2}{c}{ with migration background } & & native \\
& Model 1 & Model 2 & Model 3 & Model 4 \\
Change of aspirations of friends & 0.03 & 0.03 & $0.10^{* * *}$ & $0.10^{* * *}$ \\
& $(0.03)$ & $(0.03)$ & $(0.02)$ & $(0.02)$ \\
Change of aspirations of class & & -0.01 & & 0.04 \\
& & $(0.08)$ & & $(0.06)$ \\
Intercept & $0.06^{* * *}$ & $0.06^{* * *}$ & $0.07^{* * *}$ & $0.07^{* * *}$ \\
& $(0.01)$ & $(0.01)$ & $(0.01)$ & $(0.01)$ \\
\hline $\mathrm{R}^{2}$ & & & & 0.00 \\
Adj. R & & & 0.00 & 0.00 \\
Num. obs. & 0.00 & 0.00 & 0.00 & 4744 \\
\hline
\end{tabular}

${ }^{* * *} \mathrm{p}<0.001,{ }^{* *} \mathrm{p}<0.01,{ }^{*} \mathrm{p}<0.05$

Notes: Class-room level average aspirations were computed leaving out individual aspirations as well as friends' aspirations. 
Table A.4. Logistic regression predicting individual university aspirations at wave 2 (reporting average marginal effects, standard errors clustered on class level).

\begin{tabular}{|c|c|c|c|c|}
\hline & Model 1 & Model 2 & Model 3 & Model 4 \\
\hline friends: av. university aspirations & $\begin{array}{l}0.49 * * * \\
(0.02)\end{array}$ & $\begin{array}{l}0.18^{* * *} \\
(0.02)\end{array}$ & $\begin{array}{l}0.12^{* * *} \\
(0.02)\end{array}$ & $\begin{array}{l}0.12^{* * *} \\
(0.03)\end{array}$ \\
\hline individual university aspirations, w1 & & $\begin{array}{l}0.39 * * * \\
(0.01)\end{array}$ & $\begin{array}{l}0.38 * * * \\
(0.01)\end{array}$ & $\begin{array}{l}0.38 * * * \\
(0.01)\end{array}$ \\
\hline sex (female) & & $\begin{array}{l}0.06^{* * *} \\
(0.01)\end{array}$ & $\begin{array}{l}0.06^{* * *} \\
(0.01)\end{array}$ & $\begin{array}{l}0.06^{* * *} \\
(0.01)\end{array}$ \\
\hline age (in months) & & $\begin{array}{l}-0.01^{* * *} \\
(0.00)\end{array}$ & $\begin{array}{l}-0.00^{* * *} \\
(0.00)\end{array}$ & $\begin{array}{l}-0.00^{* * *} \\
(0.00)\end{array}$ \\
\hline migration background (binary) & & $\begin{array}{l}0.09^{* * *} \\
(0.02)\end{array}$ & $\begin{array}{l}0.09^{* * *} \\
(0.02)\end{array}$ & $\begin{array}{l}0.09^{* * *} \\
(0.03)\end{array}$ \\
\hline cognitive ability index & & $\begin{array}{l}0.01^{* * *} \\
(0.00)\end{array}$ & $\begin{array}{l}0.01^{* * *} \\
(0.00)\end{array}$ & $\begin{array}{l}0.01^{* * *} \\
(0.00)\end{array}$ \\
\hline at least one parent has a university degree & & $\begin{array}{l}0.07^{* * *} \\
(0.02)\end{array}$ & $\begin{array}{l}0.06^{* * *} \\
(0.02)\end{array}$ & $\begin{array}{l}0.06^{* * *} \\
(0.02)\end{array}$ \\
\hline parental university aspirations & & $\begin{array}{l}0.16^{* * *} \\
(0.02)\end{array}$ & $\begin{array}{l}0.15^{* * *} \\
(0.02)\end{array}$ & $\begin{array}{l}0.15^{* * *} \\
(0.02)\end{array}$ \\
\hline friends: av. cognitive ability & & $\begin{array}{l}-0.05 \\
(0.03)\end{array}$ & $\begin{array}{l}-0.05 \\
(0.03)\end{array}$ & $\begin{array}{l}-0.05 \\
(0.03)\end{array}$ \\
\hline friends: prop. natives & & $\begin{array}{l}0.01^{* * *} \\
(0.00)\end{array}$ & $\begin{array}{l}0.01^{* *} \\
(0.00)\end{array}$ & $\begin{array}{l}0.01^{* *} \\
(0.00)\end{array}$ \\
\hline friends: prop. with parental degree & & $\begin{array}{l}0.14^{* * *} \\
(0.03)\end{array}$ & $\begin{array}{l}0.13^{* * *} \\
(0.03)\end{array}$ & $\begin{array}{l}0.13^{* * *} \\
(0.03)\end{array}$ \\
\hline class: av. university aspirations (- friends) & & & $\begin{array}{l}0.35^{* * *} \\
(0.06)\end{array}$ & $\begin{array}{l}0.35^{* * *} \\
(0.06)\end{array}$ \\
\hline class: prop. native students (- friends) & & & $\begin{array}{l}0.09 \\
(0.06)\end{array}$ & $\begin{array}{l}0.09 \\
(0.06)\end{array}$ \\
\hline class: av. cognitive ability (- friends) & & & $\begin{array}{l}-0.00 \\
(0.00)\end{array}$ & $\begin{array}{l}-0.00 \\
(0.00)\end{array}$ \\
\hline class: prop. with parental degree (- friends) & & & $\begin{array}{l}-0.06 \\
(0.07)\end{array}$ & $\begin{array}{l}-0.06 \\
(0.07)\end{array}$ \\
\hline friends: av. university aspirations * migr.b. & & & & $\begin{array}{l}-0.01 \\
(0.05)\end{array}$ \\
\hline Num. obs. & 7147 & 7147 & 7147 & 7147 \\
\hline Log Likelihood & -4071.7 & -3191.0 & -3164.9 & -3164.9 \\
\hline Deviance & 8143.4 & 6382.1 & 6329.9 & 6329.9 \\
\hline AIC & 8153.4 & 6412.1 & 6367.9 & 6369.9 \\
\hline $\mathrm{BIC}$ & 8187.8 & 6515.2 & 6498.6 & 6507.4 \\
\hline
\end{tabular}

*** $\mathrm{p}<0.001,{ }^{* *} \mathrm{p}<0.01,{ }^{*} \mathrm{p}<0.05$

Notes: Class-room level averages were computed leaving out the individual as well as friends. All predictor variables are based on measures from wave 1. Models control for sampling stratum and country. Abbreviation: prop = proportion, av. $=$ average, migr.b. $=$ migration background . 
Table A.5. Logistic regression predicting individual university aspirations at wave 2, reporting average marginal effects. Subsample: Native individuals.

\begin{tabular}{|c|c|c|c|}
\hline & Model 1 & Model 2 & Model 3 \\
\hline friends: av. university aspirations & $\begin{array}{l}0.54^{* * *} \\
(0.03)\end{array}$ & $\begin{array}{l}0.18^{* * *} \\
(0.03)\end{array}$ & $\begin{array}{l}0.11^{* * *} \\
(0.03)\end{array}$ \\
\hline individual university aspirations, w1 & & $\begin{array}{l}0.41^{* * *} \\
(0.02)\end{array}$ & $\begin{array}{l}0.40^{* * *} \\
(0.02)\end{array}$ \\
\hline gender (female) & & $\begin{array}{l}0.08^{* * *} \\
(0.02)\end{array}$ & $\begin{array}{l}0.08^{* * *} \\
(0.02)\end{array}$ \\
\hline age (in months) & & $\begin{array}{l}-0.01^{* * *} \\
(0.00)\end{array}$ & $\begin{array}{l}-0.00^{* *} \\
(0.00)\end{array}$ \\
\hline cognitive ability index & & $\begin{array}{l}0.01^{* * *} \\
(0.00)\end{array}$ & $\begin{array}{l}0.01^{* *} \\
(0.00)\end{array}$ \\
\hline at least one parent has a university degree & & $\begin{array}{l}0.09^{* * *} \\
(0.02)\end{array}$ & $\begin{array}{l}0.09^{* * *} \\
(0.02)\end{array}$ \\
\hline parental university aspirations & & $\begin{array}{l}0.17^{* * *} \\
(0.02)\end{array}$ & $\begin{array}{l}0.17^{* * *} \\
(0.02)\end{array}$ \\
\hline \multicolumn{4}{|l|}{ peer milieu: friends } \\
\hline friends: av. cognitive ability & & $\begin{array}{l}-0.02 \\
(0.04)\end{array}$ & $\begin{array}{l}-0.03 \\
(0.04)\end{array}$ \\
\hline friends: prop. natives & & $\begin{array}{l}0.01^{* * *} \\
(0.00)\end{array}$ & $\begin{array}{l}0.01^{*} \\
(0.00)\end{array}$ \\
\hline friends: prop. with parental degree & & $\begin{array}{l}0.18^{* * *} \\
(0.04)\end{array}$ & $\begin{array}{l}0.17^{* * *} \\
(0.04)\end{array}$ \\
\hline \multicolumn{4}{|l|}{ school class } \\
\hline class: av. university aspirations & & & $\begin{array}{l}0.39^{* * *} \\
(0.08)\end{array}$ \\
\hline class: prop. natives & & & $\begin{array}{l}0.15 \\
(0.08)\end{array}$ \\
\hline class: av. cognitive ability & & & $\begin{array}{l}0.00 \\
(0.01)\end{array}$ \\
\hline class: prop. with parental degree & & & $\begin{array}{l}-0.04 \\
(0.09)\end{array}$ \\
\hline Num. obs. & 4729 & 4729 & 4729 \\
\hline Log Likelihood & -2746.61 & -2149.19 & -2127.03 \\
\hline Deviance & 5493.22 & 4300.37 & 4256.06 \\
\hline AIC & 5503.22 & 4328.37 & 4292.06 \\
\hline BIC & 5535.53 & 4425.29 & 4414.83 \\
\hline
\end{tabular}

${ }^{* * *} \mathrm{p}<0.001,{ }^{* *} \mathrm{p}<0.01,{ }^{*} \mathrm{p}<0.05$

All models control for survey country and sampling stratum. 
Table A.6. Logistic regression predicting individual university aspirations at wave 2, reporting average marginal effects. Subsample: Ethnic minority individuals.

\begin{tabular}{|c|c|c|c|}
\hline & Model 1 & Model 2 & Model 3 \\
\hline friends: av. university aspirations & $\begin{array}{l}0.36^{* * *} \\
(0.03)\end{array}$ & $\begin{array}{l}0.15^{* * *} \\
(0.04)\end{array}$ & $\begin{array}{l}0.12^{* *} \\
(0.04)\end{array}$ \\
\hline individual university aspirations, w1 & & $\begin{array}{l}0.35^{* * *} \\
(0.03)\end{array}$ & $\begin{array}{l}0.35^{* * *} \\
(0.03)\end{array}$ \\
\hline gender (female) & & $\begin{array}{l}0.02 \\
(0.02)\end{array}$ & $\begin{array}{l}0.02 \\
(0.02)\end{array}$ \\
\hline age (in months) & & $\begin{array}{l}-0.00^{* *} \\
(0.00)\end{array}$ & $\begin{array}{l}-0.00^{*} \\
(0.00)\end{array}$ \\
\hline cognitive ability index & & $\begin{array}{l}0.01^{*} \\
(0.00)\end{array}$ & $\begin{array}{l}0.01^{*} \\
(0.00)\end{array}$ \\
\hline at least one parent has a university degree & & $\begin{array}{l}0.02 \\
(0.02)\end{array}$ & $\begin{array}{l}0.01 \\
(0.02)\end{array}$ \\
\hline parental university aspirations & & $\begin{array}{l}0.14^{* * *} \\
(0.02)\end{array}$ & $\begin{array}{l}0.13^{* * *} \\
(0.02)\end{array}$ \\
\hline peer milieu: friends & & & \\
\hline friends: av. cognitive ability & & $\begin{array}{l}-0.05 \\
(0.04)\end{array}$ & $\begin{array}{l}-0.05 \\
(0.04)\end{array}$ \\
\hline friends: prop. natives & & $\begin{array}{l}0.01 \\
(0.00)\end{array}$ & $\begin{array}{l}0.01 \\
(0.00)\end{array}$ \\
\hline friends: prop. with parental degree & & $\begin{array}{l}0.05 \\
(0.04)\end{array}$ & $\begin{array}{l}0.05 \\
(0.04)\end{array}$ \\
\hline school class & & & \\
\hline class: av. university aspirations & & & $\begin{array}{l}0.28^{* *} \\
(0.09)\end{array}$ \\
\hline class: prop. natives & & & $\begin{array}{l}0.05 \\
(0.09)\end{array}$ \\
\hline class: av. cognitive ability & & & $\begin{array}{l}-0.00 \\
(0.01)\end{array}$ \\
\hline class: prop. with parental degree & & & $\begin{array}{l}-0.14 \\
(0.10)\end{array}$ \\
\hline Num. obs. & 2418 & 2418 & 2418 \\
\hline Log Likelihood & -1273.58 & -1029.22 & -1023.42 \\
\hline Deviance & 2547.15 & 2060.44 & 2048.83 \\
\hline AIC & 2557.15 & 2088.44 & 2084.83 \\
\hline BIC & 2586.11 & 2175.30 & 2194.85 \\
\hline
\end{tabular}

${ }^{* * *} \mathrm{p}<0.001,{ }^{* *} \mathrm{p}<0.01,{ }^{*} \mathrm{p}<0.05$

All models control for survey country and sampling stratum. 
Table A.7. Logistic regression predicting individual university aspirations at wave 2 (reporting average marginal effects, standard errors clustered on class level).

\begin{tabular}{|c|c|c|c|c|}
\hline & Model 1 & Model 2 & Model 3 & Model 4 \\
\hline Friendship group: av. university aspirations & $\begin{array}{l}0.39^{* * *} \\
(0.02)\end{array}$ & $\begin{array}{l}0.17^{* * *} \\
(0.02)\end{array}$ & $\begin{array}{l}0.12^{* * *} \\
(0.02)\end{array}$ & $\begin{array}{l}0.11^{* * *} \\
(0.02)\end{array}$ \\
\hline Individual university aspirations, w1 & & $\begin{array}{l}0.39^{* * *} \\
(0.01)\end{array}$ & $\begin{array}{l}0.38^{* * *} \\
(0.01)\end{array}$ & $\begin{array}{l}0.38^{* * *} \\
(0.01)\end{array}$ \\
\hline Sex (female) & & $\begin{array}{l}0.06^{* * *} \\
(0.01)\end{array}$ & $\begin{array}{l}0.06^{* * *} \\
(0.01)\end{array}$ & $\begin{array}{l}0.06^{* * *} \\
(0.01)\end{array}$ \\
\hline Age (in months) & & $\begin{array}{l}-0.01^{* * *} \\
(0.00)\end{array}$ & $\begin{array}{l}-0.00^{* * *} \\
(0.00)\end{array}$ & $\begin{array}{l}-0.00^{* * *} \\
(0.00)\end{array}$ \\
\hline Migration background (binary) & & $\begin{array}{l}0.10^{* * *} \\
(0.02)\end{array}$ & $\begin{array}{l}0.09^{* * * *} \\
(0.02)\end{array}$ & $\begin{array}{l}0.09^{* * *} \\
(0.02)\end{array}$ \\
\hline Cognitive ability index & & $\begin{array}{l}0.01^{* * *} \\
(0.00)\end{array}$ & $\begin{array}{l}0.01^{* * *} \\
(0.00)\end{array}$ & $\begin{array}{l}0.01^{* * *} \\
(0.00)\end{array}$ \\
\hline At least one parent has a university degree & & $\begin{array}{l}0.07^{* * *} \\
(0.02)\end{array}$ & $\begin{array}{l}0.06^{* * *} \\
(0.02)\end{array}$ & $\begin{array}{l}0.06^{* * *} \\
(0.02)\end{array}$ \\
\hline Parental university aspirations & & $\begin{array}{l}0.16^{* * *} \\
(0.02)\end{array}$ & $\begin{array}{l}0.15^{* * *} \\
(0.02)\end{array}$ & $\begin{array}{l}0.15^{* * *} \\
(0.02)\end{array}$ \\
\hline Friendship group: prop. natives & & $\begin{array}{l}0.01^{* * *} \\
(0.00)\end{array}$ & $\begin{array}{l}0.01^{* * *} \\
(0.00)\end{array}$ & $\begin{array}{l}0.01^{* * *} \\
(0.00)\end{array}$ \\
\hline Friendship group: av. cognitive ability & & $\begin{array}{l}0.08^{* *} \\
(0.02)\end{array}$ & $\begin{array}{l}0.06^{*} \\
(0.02)\end{array}$ & $\begin{array}{l}0.06^{*} \\
(0.02)\end{array}$ \\
\hline Friendship group: prop. with parental degree & & & $\begin{array}{l}-0.03 \\
(0.02)\end{array}$ & $\begin{array}{l}-0.03 \\
(0.02)\end{array}$ \\
\hline Class: av. university aspirations (- fr.group) & & & $\begin{array}{l}0.26^{* * *} \\
(0.05)\end{array}$ & $\begin{array}{l}0.26^{* * *} \\
(0.05)\end{array}$ \\
\hline Class: prop. native students (- fr.group) & & & $\begin{array}{l}0.05 \\
(0.04)\end{array}$ & $\begin{array}{l}0.05 \\
(0.04)\end{array}$ \\
\hline Class: av. cognitive ability (- fr.group) & & & $\begin{array}{l}-0.00 \\
(0.00)\end{array}$ & $\begin{array}{l}-0.00 \\
(0.00)\end{array}$ \\
\hline Class: prop. with parental degree (- fr.group) & & & $\begin{array}{l}0.01 \\
(0.06)\end{array}$ & $\begin{array}{l}0.01 \\
(0.06)\end{array}$ \\
\hline Friendship group: av. university aspirations * migr.b. & & & & $\begin{array}{l}0.01 \\
(0.04)\end{array}$ \\
\hline Num. obs. & 7147 & 7147 & 7147 & 7147 \\
\hline Log Likelihood & -4128.7 & -3196.9 & -3169.6 & -3169.6 \\
\hline Deviance & 8257.3 & 6393.7 & 6339.3 & 6339.2 \\
\hline AIC & 8267.3 & 6421.7 & 6377.3 & 6379.2 \\
\hline BIC & 8301.7 & 6517.9 & 6507.9 & 6516.7 \\
\hline
\end{tabular}

${ }^{* * *} \mathrm{p}<0.001,{ }^{* *} \mathrm{p}<0.01,{ }^{*} \mathrm{p}<0.05$

Notes: Clique-level averages were computed leaving out the individual. Class-room level averages were computed with leaving out the individual as well as the clique. All predictor variables are based on measures from wave 1 . Models control for sampling stratum and survey country. Abbreviations: prop = proportion, av. = average, fr.group $=$ friendship group, migr.b. $=$ migration background . 
Table A.8. Logistic regression predicting individual university aspirations at wave 2, reporting average marginal effects. Subsample: Native individuals.

\begin{tabular}{|c|c|c|c|}
\hline & Model 1 & Model 2 & Model 3 \\
\hline fr. group: av. university aspirations & $\begin{array}{l}0.42^{* * *} \\
(0.03)\end{array}$ & $\begin{array}{l}0.17^{* * *} \\
(0.03)\end{array}$ & $\begin{array}{l}0.10^{* * *} \\
(0.03)\end{array}$ \\
\hline individual university aspirations, w1 & & $\begin{array}{l}0.41^{* * *} \\
(0.02)\end{array}$ & $\begin{array}{l}0.40^{* * *} \\
(0.02)\end{array}$ \\
\hline gender (female) & & $\begin{array}{l}0.08^{* * *} \\
(0.02)\end{array}$ & $\begin{array}{l}0.08^{* * *} \\
(0.02)\end{array}$ \\
\hline age (in months) & & $\begin{array}{l}-0.01^{* * *} \\
(0.00)\end{array}$ & $\begin{array}{l}-0.00^{* *} \\
(0.00)\end{array}$ \\
\hline cognitive ability index & & $\begin{array}{l}0.01^{* * *} \\
(0.00)\end{array}$ & $\begin{array}{l}0.01^{* *} \\
(0.00)\end{array}$ \\
\hline at least one parent has a university degree & & $\begin{array}{l}0.10^{* * *} \\
(0.02)\end{array}$ & $\begin{array}{l}0.09^{* * *} \\
(0.02)\end{array}$ \\
\hline parental university aspirations & & $\begin{array}{l}0.17^{* * *} \\
(0.02)\end{array}$ & $\begin{array}{l}0.16^{* * *} \\
(0.02)\end{array}$ \\
\hline peer milieu: friendship group & & & \\
\hline fr.group: av. cognitive ability & & $\begin{array}{l}0.01^{* * *} \\
(0.00)\end{array}$ & $\begin{array}{l}0.01^{*} \\
(0.00)\end{array}$ \\
\hline fr.group: prop. with parental degree & & $\begin{array}{l}0.12^{* * *} \\
(0.03)\end{array}$ & $\begin{array}{l}0.10^{* *} \\
(0.03)\end{array}$ \\
\hline fr.group: prop. natives & & & $\begin{array}{l}-0.03 \\
(0.03)\end{array}$ \\
\hline school class & & & \\
\hline class: av. university aspirations & & & $\begin{array}{l}0.27^{* * *} \\
(0.06)\end{array}$ \\
\hline class: prop. natives & & & $\begin{array}{l}0.08 \\
(0.06)\end{array}$ \\
\hline class: av. cognitive ability & & & $\begin{array}{l}0.01 \\
(0.01)\end{array}$ \\
\hline class: prop. with parental degree & & & $\begin{array}{l}0.05 \\
(0.07)\end{array}$ \\
\hline Num. obs. & 4729 & 4729 & 4729 \\
\hline Log Likelihood & -2796.53 & -2156.72 & -2131.56 \\
\hline Deviance & 5593.05 & 4315.45 & 4265.13 \\
\hline AIC & 5603.05 & 4341.45 & 4301.13 \\
\hline BIC & 5635.36 & 4431.91 & 4423.90 \\
\hline
\end{tabular}

${ }^{* * *} \mathrm{p}<0.001,{ }^{* *} \mathrm{p}<0.01,{ }^{*} \mathrm{p}<0.05$

All models control for survey country and sampling stratum. Abbreviations: fr.group = friendship group. 
Table A.9. Logistic regression predicting individual university aspirations at wave 2, reporting average marginal effects. Subsample: Ethnic minority individuals.

\begin{tabular}{|c|c|c|c|}
\hline & Model 1 & Model 2 & Model 3 \\
\hline fr. group: av. university aspirations & $\begin{array}{l}0.29^{* * *} \\
(0.03)\end{array}$ & $\begin{array}{l}0.16^{* * *} \\
(0.03)\end{array}$ & $\begin{array}{l}0.13^{* * *} \\
(0.03)\end{array}$ \\
\hline individual university aspirations, w1 & & $\begin{array}{l}0.35^{* * *} \\
(0.03)\end{array}$ & $\begin{array}{l}0.35^{* * *} \\
(0.03)\end{array}$ \\
\hline gender (female) & & $\begin{array}{l}0.02 \\
(0.02)\end{array}$ & $\begin{array}{l}0.02 \\
(0.02)\end{array}$ \\
\hline age (in months) & & $\begin{array}{l}-0.00^{*} \\
(0.00)\end{array}$ & $\begin{array}{l}-0.00^{*} \\
(0.00)\end{array}$ \\
\hline cognitive ability index & & $\begin{array}{l}0.01^{*} \\
(0.00)\end{array}$ & $\begin{array}{l}0.01^{* *} \\
(0.00)\end{array}$ \\
\hline at least one parent has a university degree & & $\begin{array}{l}0.02 \\
(0.02)\end{array}$ & $\begin{array}{l}0.01 \\
(0.02)\end{array}$ \\
\hline parental university aspirations & & $\begin{array}{l}0.14^{* * *} \\
(0.02)\end{array}$ & $\begin{array}{l}0.14^{* * *} \\
(0.02)\end{array}$ \\
\hline \multicolumn{4}{|l|}{ peer milieu: friendship group } \\
\hline fr.group: av. cognitive ability & & $\begin{array}{l}0.01^{*} \\
(0.00)\end{array}$ & $\begin{array}{l}0.01^{*} \\
(0.00)\end{array}$ \\
\hline fr.group: prop. with parental degree & & $\begin{array}{l}-0.01 \\
(0.04)\end{array}$ & $\begin{array}{l}-0.01 \\
(0.04)\end{array}$ \\
\hline fr.group: prop. natives & & & $\begin{array}{l}-0.02 \\
(0.03)\end{array}$ \\
\hline \multicolumn{4}{|l|}{ school class } \\
\hline class: av. university aspirations & & & $\begin{array}{l}0.20^{* *} \\
(0.07)\end{array}$ \\
\hline class: prop. natives & & & $\begin{array}{l}0.05 \\
(0.07)\end{array}$ \\
\hline class: av. cognitive ability & & & $\begin{array}{l}-0.01 \\
(0.01)\end{array}$ \\
\hline class: prop. with parental degree & & & $\begin{array}{l}-0.09 \\
(0.08)\end{array}$ \\
\hline Num. obs. & 2418 & 2418 & 2418 \\
\hline Log Likelihood & -1282.04 & -1026.53 & -1021.66 \\
\hline Deviance & 2564.08 & 2055.05 & 2045.33 \\
\hline AIC & 2574.08 & 2081.05 & 2081.33 \\
\hline BIC & 2603.03 & 2162.12 & 2191.35 \\
\hline
\end{tabular}

${ }^{* * *} \mathrm{p}<0.001,{ }^{* *} \mathrm{p}<0.01,{ }^{*} \mathrm{p}<0.05$

All models control for survey country and sampling stratum. Abbreviations: fr.group = friendship group. 


\section{Bibliography (Appendix)}

Griga, D., \& Hadjar, A. (2014). Migrant background and higher education participation in Europe: the effect of the educational systems. European Sociological Review.

http://doi.org/10.1093/esr/jct031 